Received Date : 13-0ct-2016

Revised Date : 08-Dec-2016

Accepted Date : 19-Dec-2016

Article type : Original Article

\title{
What do patients think about the role of optometrists in providing advice about smoking and nutrition?
}

\author{
Laura E Downie Amanda Douglass, Daryl Guest, Peter R Keller
}

Department of Optometry and Vision Sciences, The University of Melbourne, Parkville, Australia.

Keywords: optometry, evidence-based practice, optometrist, public perception, scope of practice, smoking, diet, nutritional supplement, age-related macular degeneration

*Correspondence and reprint requests to:

Laura Downie

Email: $\underline{\text { ldownie@ unimelb.edu.au }}$

\section{ABSTRACT}

This is the author manuscript accepted for publication and has undergone full peer review but has not been through the copyediting, typesetting, pagination and proofreading process, which may lead to differences between this version and the Version of Record. Please cite this article as doi: 10.1111/opo.12353

This article is protected by copyright. All rights reserved 
Purpose: Tobacco smoking and nutrition are key lifestyle factors with long-term effects on eye health. However, little is known about patients' perceptions and experiences in these areas in relation to the care received from optometrists. The main aim was to survey patients' perceptions and prior experience regarding the role of optometrists in enquiring and providing advice about tobacco smoking and nutrition.

Methods: An anonymous, paper-based survey was distributed to a convenience sample of 225 adults attending the University of Melbourne eye care clinic. Respondents provided demographic and other information (age, sex, length of time since last eye examination, country of most recent eye examination, smoking status and intake of nutritional supplements) and indicated their level of agreement (using a five-step Likert scale) with a series of statements relating to the care provided by optometrists in the areas of health, smoking and nutrition. The statements were designed to assess the perceived scope of practice of optometrists and the extent to which patients expect, and feel comfortable, discussing these issues with their optometrist.

Results: 220 completed surveys were returned. Most respondents (>80\%) agreed that they visit their optometrist to quantify their refractive error and to examine their eye health. About two-thirds of respondents indicated that they expect their optometrist to ask about their general health, with almost half expecting their optometrist to communicate with their general medical practitioner. Approximately one-third of respondents indicated having been routinely questioned about their smoking status, diet and nutritional supplement intake by their optometrist. This was despite about half expecting their optometrist to question them about these factors and almost three out of four respondents indicating that they felt comfortable talking with their optometrist about these lifestyle behaviours.

Conclusions: This study provides novel insight into patients' perceptions and experience with optometric practice in the areas of tobacco smoking and nutrition. The majority of respondents expected their optometrist to examine their eye health, ask them about their smoking and diet habits, and indicated feeling comfortable discussing these topics with their primary eye care provider. These findings suggest 
that brief advice interventions relating to tobacco use and diet are likely to be acceptable to deliver in optometry practice.

\section{MAIN TEXT}

\section{INTRODUCTION}

Optometric scope of practice varies greatly in different parts of the world, and there is not a universal, common definition of what an optometrist 'is' or 'does.' ${ }^{\text {I In some }}$ countries optometry consists solely of rudimentary eyesight testing and the provision of spectacles and/or contact lenses for refractive correction. In contrast, in some states of the United States of America (USA), optometrists are accredited to perform minor ocular surgeries. Further, the scope of practice of optometrists is continuing to expand and with this comes a wider range of extended clinical responsibilities that encompass ocular disease diagnosis and management. ${ }^{2}$

In Australia, the professional scope of optometry practice has evolved over the past several decades, and currently includes the independent diagnosis, assessment and management of ocular disorders relating to visual function and eye health, including the prescription of scheduled topical medicines. ${ }^{5}$ However, it is unclear whether the public's perception of optometric practice has kept pace with the changes that have occurred in scope of practice. There is currently no literature, from any region worldwide, investigating patient expectations in relation to the care they expect to receive when they attend for an eye examination with an optometrist. For example, are patients seeking only refractive care, and therefore do not expect and/or do not feel comfortable discussing general health and lifestyle factors that can potentially influence eye health with their optometrist? Alternatively, do patients perceive the role of their optometrist as a part of their primary health care team and, in doing so, expect evidence-based questioning and advice about how their general health and certain lifestyle behaviours could be impacting upon their ocular health?

These questions are particularly relevant to two key modifiable risk factors, tobacco use and nutrition, which have long-term effects on ocular health. Tobacco smoking is linked to several serious ocular pathologies, in particular age-related macular degeneration (AMD). ${ }^{6-8}$ AMD accounts for more than half of adult blindness in 
developed countries. ${ }^{9}$ With ageing global demographics, the number of people with AMD is predicted to almost double by $2035 .{ }^{9}$ While treatments currently exist for the neovascular form of late-stage AMD, therapies for earlier stages of AMD are still considered experimental. Furthermore, projections show that in some regions, tertiary health services are likely to be exhausted by patient need for treatments relating only to neovascular AMD by $2030 .{ }^{9}$ In the absence of a cure, preventing progression to late-stage AMD is therefore the most valuable approach for reducing vision loss and the associated individual and community burden of this disease.

Tobacco contains toxic, carcinogenic and mutagenic chemicals that induce biological damage. Tobacco is most commonly smoked, from cigarettes or cigars, but can also be chewed, with significant health risks associated with each of these behaviours. Tobacco smoking is the single most important modifiable risk factor for AMD. ${ }^{10}$ Current smokers have between a two- and four-fold increased risk of developing AMD compared with people who have never smoked. ${ }^{11,12}$ A direct relationship exists between the risk of developing late-stage disease and the number of cigarettes smoked over time. ${ }^{13}$ Importantly, these risks are strongly modifiable. The risk of developing AMD decreases substantially following smoking cessation and is also lowered by a reduction in smoking intensity. ${ }^{14,15}$ After 20 years of cessation, the risk of developing AMD is similar to a person who has never smoked. ${ }^{16}$ Such risk reduction has been proposed to potentially provide a highly valuable health message to encourage smoking cessation. Despite the established link between tobacco smoking and adverse ocular health outcomes, recent studies that have surveyed eye care clinicians in different parts of the world ${ }^{17-23}$ report similar deficiencies in care provision in this practice area. Our research, which investigated self-reported optometric practices in Australia, indicates that only about half of optometrists routinely enquire about their patient's smoking behaviours. ${ }^{21}$ In this study, one barrier cited by clinicians who reported not providing smoking cessation counselling was that they felt patients might consider the discussion of this topic too personal or intrusive. However, it is not currently known whether this is a true barrier, as there is no prior research investigating how people attending for eye care feel about discussing tobacco use with their optometrist. Indeed, while the concern of intruding on a patient's lifestyle choice has been cited by practitioners as a potential barrier that could damage the patient- 
provider relationship, in the context of advice provided by a general medical practitioner, this has been reported not to be the case. ${ }^{24}$

Over the past decade, there has also been heightened interest in the influence of nutrition on health, including eye health, and the utility of nutrition-based strategies for managing eye disease. As recently reviewed, ${ }^{8}$ epidemiological data have shown strong associations between diets rich in the macular carotenoids (zeaxanthin and lutein) and omega-3 long-chain essential fatty acids, and a reduced long-term risk of late-stage AMD. In addition, the Age-Related Eye Disease Study (AREDS) ${ }^{13}$ showed that daily consumption of a specific formulation of high-dose antioxidant vitamins and minerals, reduced the risk of progression from intermediate- to late-stage AMD from $28 \%$ to $20 \%$ over a five year period. Importantly, this study showed that the potential benefit of nutritional supplementation was only for specific populations of high-risk AMD patients, rather than the general population, and that recommendations should be considered in the context of other health factors, including smoking behaviours. Another relevant example is growing evidence ${ }^{25,26}$ and the increased adoption $^{27,28}$ of omega-3 essential fatty acids supplements for modulating ocular surface inflammation in dry eye disease.

Given the links between nutrition and ocular disease, optometrists should also assume a role in discussing these associations with their patients and providing advice about the merit, or otherwise, of different foods and/or nutritional supplements for modifying eye health. We previously reported that 60 percent of Australian optometrists self-reported routinely counselling patients about their diet. ${ }^{21}$ However, as for smoking cessation, little is currently known about whether patients expect, and/or are receptive, to engage in discussions about diet with their optometrist in the context of its implications on eye health.

The major aim of this study was to assess public perception with regard to the role of optometrists in enquiring and providing advice in the areas of tobacco smoking and nutrition, being important lifestyle factors with significant, long-term effects upon ocular health. We also sought to assess whether patients expect their optometrist to ask them about their general health, and to communicate with their general medical 
practitioner and/or other allied health practitioners to assist them with making lifestyle changes that can affect their ocular health.

\section{METHODS}

This project was reviewed and approved by the University of Melbourne Human Research Ethics Committee (HREC \#1545591.1).

\section{Participants}

An anonymous, voluntary, paper-based survey was distributed to a convenience sample of 225 adults (aged 18 years or over) who attended the University of Melbourne eye care (UMeyecare) clinic, a private community-based optometry clinic. Potential participants were invited to partake in the study by the clinic reception staff, when presenting for an appointment, between 15 December 2015 and 1 March 2016. Distribution of the survey to patients was dependent upon reception staff providing a verbal invitation to participate. Although the number of potential participants who declined to participate was not formally recorded, qualitative feedback from the staff indicated that very few (estimated to be five or fewer) patients elected not to participate after a verbal invitation. Over this period, a total of 534 adults attended the UMeyecare clinic, giving a sampling proportion of 42 percent of all attending patients. Potential participants were advised that the survey would take approximately five minutes to complete. A written statement on the first page of the survey informed potential participants that the completion and submission of the survey, in a respondent box at reception, implied their consent to participate.

\section{Survey instrument}

The survey, which is provided for readers as supplementary material, was designed and pilot tested by the authors, based upon previous survey-based research. ${ }^{21,29}$ For topic areas (i) Expectations and perceptions, and (ii) Prior experiences, the survey questions were constructed on a five-step Likert scale, assessing perceptions, expectations and/or experiences in each domain.

The survey covered the following topic areas, relevant to the public perceptions of optometric clinical care:

i) Expectations and perceptions 
a. whether people recognise the role of optometrists beyond prescribing glasses and contact lenses (i.e., eye health assessment);

b. whether people expect their optometrist to ask them about their smoking and diet behaviours;

c. whether optometrists are considered to have a role in providing health information to general medical practitioners (GPs);

d. whether optometrists are perceived to have a role in referring patients to other allied health professionals for support to change lifestyle behaviours that can negatively impact upon eye health.

e. how comfortable people feel to discuss their smoking and diet behaviours with their optometrist.

\section{ii) Prior experiences}

a. whether people have been previously informed about the ocular risks associated with tobacco smoking by their optometrist;

b. whether people consider that their optometrist typically asks them whether they smoke, about their diet and their nutritional supplement intake;

c. whether people have been advised by their optometrist that their smoking status, diet and consumption of nutritional supplements can affect their eye health;

d. whether people are aware that tobacco smoking can cause blindness.

iii) Demographics

a. patient age (years);
b. patient sex (female/male);
c. country of most recent eye examination;
d. time since last eye examination (years);
e. patient's smoking status (current, former, never);
f. patient's nutritional supplement behaviours (routinely takes
supplements/does not take supplements).


The rationale for including a question relating to the country of the respondent's most recent eye examination was to recognise that the UMeyecare clinic provides care to an international population, and to therefore account for potential differences in optometric care in different geographic areas.

For the purpose of the survey a 'nutritional supplement' was defined as "any nonprescription vitamin or dietary supplement." Respondents were provided with the following internationally accepted definitions, ${ }^{30}$ as the basis for defining smoking status:

- A 'current smoker' is a person who has smoked at least one cigarette per day, or smoked at least one cigar per week, or chewed at least 30 grams of tobacco for at least one month during the past year.

- A 'former smoker', is a person who has not smoked for at least one year, but previously smoked at least one cigarette per day, or smoked at least one cigar per week, or chewed at least 30 grams of tobacco per month for at least one year.

- A 'never smoker', is a person who has smoked less than one cigarette per day and smoked less than one cigar per week and chewed less than 30 grams of tobaeco per month for no more than one year.

\section{Data analysis}

Only completed surveys $(n=220)$ were used in the analyses. Statistical analysis was performed using MiniTab Statistical Software (Version 17.0, http://www.minipad.com). Graphs were plotted using GraphPad Prism (Version 5.0 for Mac,; http://www.graphpad.com/scientific-software/prism/). Quantitative data are summarised using descriptive statistics. Chi-squared tests were used to compare data consisting of proportions (e.g., patient sex, smoking status). Data normality was tested using the Kolmogorov-Smirnov test. Unless otherwise stated, data are shown as median (interquartile range (IQR)). Proportions are reported to full integers. An alpha value of 0.05 was adopted for statistical significance.

The potential influence of a range of respondent demographic factors was analysed using ordinal linear regression. We considered each of the factors of: age 
(continuous), sex (dichotomous), time since last eye examination (categoricał 1 year, $>1$ and $\leq 2$ years, $>2$ and $\leq 3$ years, $>3$ years ago), country of most recent eye examination (categorical: Australia, Europe/United Kingdom, Asia, Other), smoking status (categorical: current, former, never) and current intake of nutritional supplements (dichotomous), as part of the model and examined the effect of each factor upon participant responses to each survey question. Effects are expressed as odds ratios (ORs) with 95\% confidence intervals (CIs). The quality of the model was assessed using the Pearson's Chi-Squared Goodness of Fit test $\left(X^{2}\right)$ and the Deviance statistic $\left(G^{2}\right)$; only models with acceptable fits (criterion: $X^{2}>0.05$ and $G^{2}>0.05$ ) are reported.

\section{RESULTS}

\section{Respondent details}

From a total of 225 surveys that were issued, 224 surveys were returned and 220 of these surveys were fully completed (completion rate: 98\%). All participants had previously attended at least one consultation with an optometrist. Table 1 summarises the survey participant demographic information. The median age of respondents was 31 years (range: 18 to 86 years) and 63\% were female. Almost two-thirds (65\%) indicated that their last eye examination had occurred within the past year (range: $<1$ to 9 years), and for most people (88\%) this had occurred in Australia. The majority $(79 \%)$ of respondents self-reported that they had never smoked, and about one-third indicated routinely taking nutritional supplements.

\begin{tabular}{|l|c|}
\hline \multicolumn{2}{|c|}{ Table 1 - Survey participant demographics } \\
\hline & $\begin{array}{c}\text { Respondents } \\
(\mathrm{n}=220)\end{array}$ \\
\hline Age, years & $31[24-47]$ \\
\hline Sex [female/male]: number $(\%)$ & $139 / 81$ \\
& $(63 \% / 37 \%)$ \\
\hline Time since last eye examination, years $^{\mathrm{a}}$ & $1[1-2]$ \\
\hline
\end{tabular}




\begin{tabular}{|c|c|}
\hline Country of most recent eye examination: number (\%) & $194(88 \%)$ \\
$-\quad$ Australia & $15(7 \%)$ \\
$-\quad$ Asia & $7(3 \%)$ \\
$-\quad$ Europe or United Kingdom & $4(2 \%)$ \\
\hline Smoking status: number (\%) & $13(6 \%)$ \\
$-\quad$ Current smoker & $33(15 \%)$ \\
\hline$\quad$ Former smoker & $174(79 \%)$ \\
\hline Routinely consume nutritional supplements: number $(\%)$ & $70(32 \%)$ \\
providing a 'Yes' response & \\
\hline
\end{tabular}

${ }^{\mathrm{a}} \mathrm{K}-\mathrm{S}$ testing indicated non-parametric distributions $(\mathrm{p}<0.0001)$. Data are shown as median (inter-quartile range).

\section{Optometric care: expectations, perceptions and prior experiences}

\section{(i) General health}

Figure 1 summarises data relating to respondents' general expectations and perceptions of optometric clinical care. The majority of respondents $(>80 \%)$ agreed (i.e., 'agree' or 'strongly agree' response) that they typically visit their optometrist to quantify their refractive error (i.e., check their spectacle and/or contact lens prescription) and to examine their eye health. Most respondents (64\%) indicated that they expect their optometrist to ask about their general health status, with about half (49\%) expecting their optometrist to communicate with their general medical practitioner (GP) about their general health. The majority (88\%) of respondents agreed that they considered it the role of their optometrist to refer them to other allied health professionals for support to change lifestyle behaviours that could negatively impact upon their eye health.

Compared with respondents who indicated having their most recent eye examination in Australia, those who reported receiving this care in Asia were significantly more 
likely to expect their optometrist to assess their eye health (OR: 5.14, 95\% CI: 1.37 19.34, p=0.02), communicate with their GP (OR: 3.49, 95\% CI: 1.11-10.92, p=0.03) and to refer them to other allied health professionals (OR: 7.42, 95\% CI: 1.80-30.67, $\mathrm{p}=0.006$ ). There were no significant associations for any of the other respondent demographic factors.

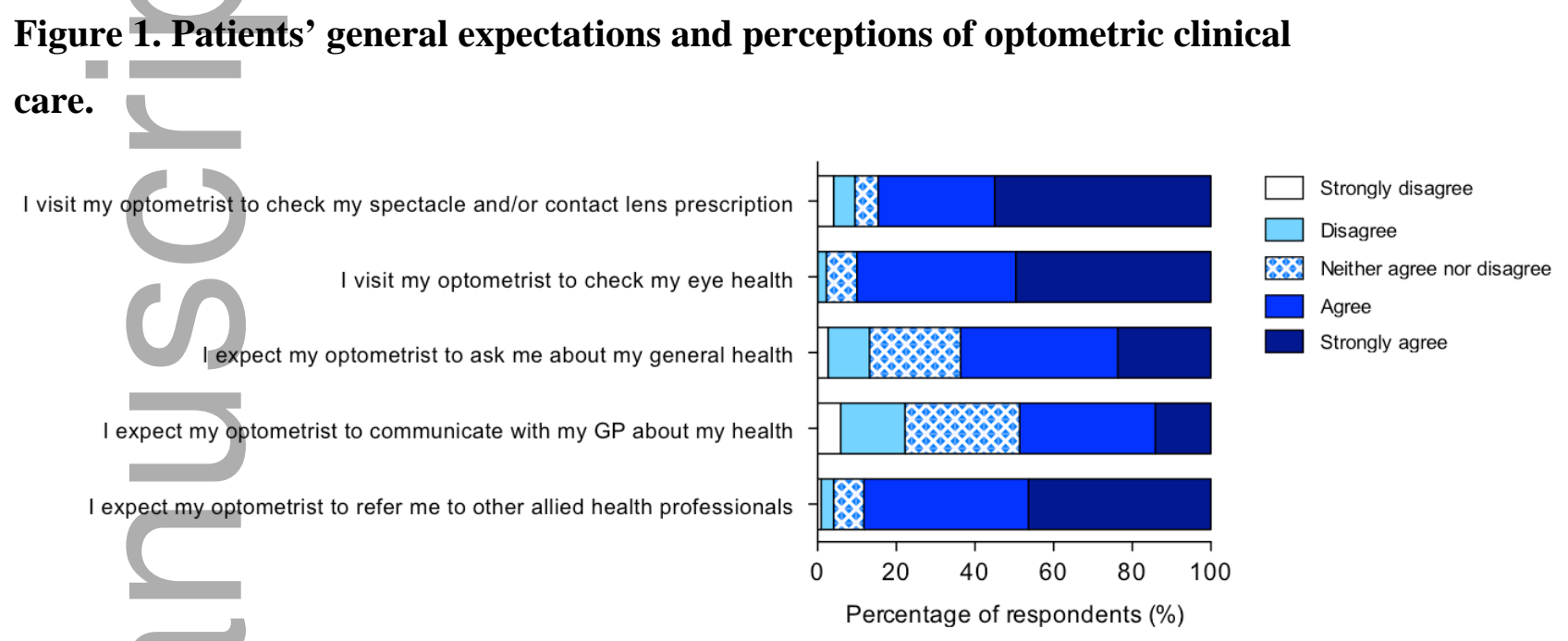

Percentage of respondents, from $n=220$, who indicated their level of agreement with each statement, using the following five-step Likert scale: strongly disagree, disagree, neither agree nor disagree, agree and strongly agree.

\section{(ii) Tobacco smoking}

Figure 2 summarises data relating to respondents' expectations, prior experience and level of comfort with discussing tobacco-smoking behaviours with their optometrist. Approximately one-third of respondents responded positively to having been routinely questioned about their smoking status by their optometrist. This was despite about half expecting their optometrist to question them about this lifestyle behaviour and $70 \%$ of respondents indicating that they felt comfortable talking to their optometrist about their smoking habits. About one in four respondents indicated that their optometrist had mentioned there are vision risks associated with smoking. Slightly more than half of respondents were aware that smoking could cause blindness.

Compared with respondents who indicated having had their most recent eye examination in Australia, those who reported receiving this care in Asia were 
significantly more likely to expect their optometrist to ask them about their smoking behaviour (OR: 4.13, 95\% CI: 1.26-13.53, p=0.02). Respondents who reported having had their last eye examination between two and three years ago, were significantly less likely to expect routine questioning about smoking status than respondents who indicated that their last eye test was in the past 12 months (OR: $0.41,95 \%$ CI: 0.20 $0.84 ; \mathrm{p}=0.01$ ). There were no significant associations for any of the other respondent demographic factors for statements relating to smoking practices.

\section{Figure 2. Patients' expectations and perceptions of optometric clinical care as related to tobacco smoking.}

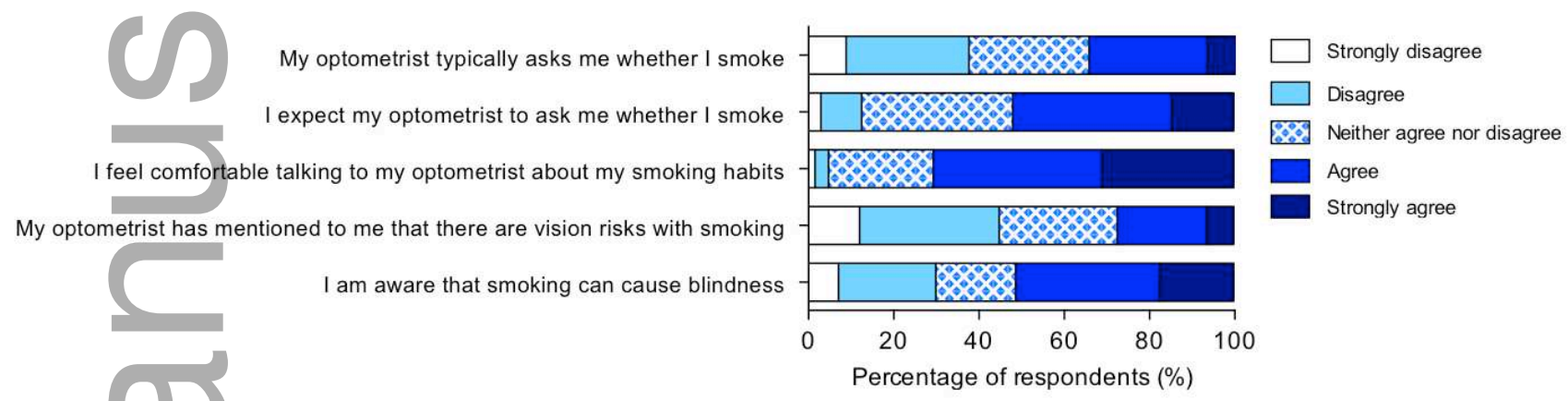

Percentage of respondents, from $n=220$, who indicated their level of agreement with each statement, using the following five-step Likert scale: strongly disagree, disagree, neither agree nor disagree, agree and strongly agree.

\section{(iii) Diet and nutritional supplementation}

Figure 3 shows data relating to respondents' expectations, prior experience, and level of comfort with discussing their diet and nutritional supplementation habits with their optometrist. Similar to the trends shown for tobacco smoking, while a minority $(\sim 20 \%)$ of respondents agreed that they were routinely questioned about their diet and/or nutritional supplement intake, a higher proportion (40\%) indicated that they expected their optometrist to ask them about these lifestyle factors and most (78\%) agreed that they felt comfortable discussing this topic with their optometrist. Fewer than one in four respondents indicated that their optometrist had mentioned that their diet could influence eye health.

Respondent age was found to be a significant factor influencing whether respondents indicated that their optometrist had mentioned that diet could affect eye health. 
Younger respondents were significantly more likely to agree that their optometrist had mentioned the influence of diet on their ocular health (OR: 1.02, 95\% CI: 1.01-1.04; $\mathrm{p}=0.03$ ). There were no significant associations for any of the other respondent demographic factors for statements relating to diet and nutritional supplementation.

\section{Figure 3. Patients' expectations and perceptions of optometric clinical care as related to diet and nutritional supplementation.}

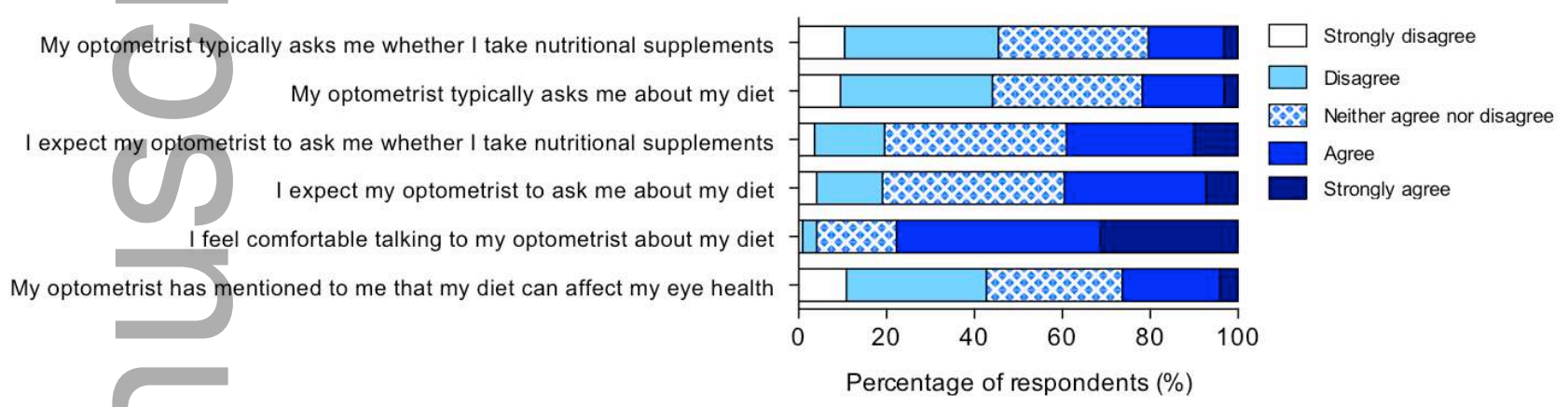

Percentage of respondents, from $n=220$, who indicated their level of agreement with each statement, using the following five-step Likert scale: strongly disagree, disagree, neither agree nor disagree, agree and strongly agree.

\section{DISCUSSION}

This study provides novel insight into patients' perceptions and experience with optometric practice in the areas of general health, tobacco smoking, and nutrition. To our knowledge, this is the first study to consider how the public perceives optometric care in these domains. Our focus on these topic areas is based upon the strong influence of these modifiable risk factors upon the long-term risk of sight threatening eye disease. Our data highlight the potential for optometrists, particularly those practicing in Australia, from where most of our data derive, to be more actively engaged in asking patients about their smoking and dietary habits and further, to provide advice about how these lifestyle factors affect eye health. Importantly, the majority of survey respondents recognised the scope of optometric practice beyond refractive care and indicated that they felt comfortable discussing their smoking and diet habits with their optometrist. Together, these findings highlight that patients attending for primary eye care examinations are expecting to receive evidence-based clinical care by optometrists in the areas of smoking cessation and diet. These are 
practice areas that are not consistently discussed with patients, yet have potential major public health implications.

Given the strong negative effects of tobacco use upon eye health, primary eye care providers, in particular optometrists, have a duty of care to discuss this behaviour with their patients. While optometrists are ideally placed to have these discussions, given that most patient interactions are routine rather than acute care presentations, in this survey only one in four respondents indicated that their optometrist had mentioned that there were vision risks associated with tobacco smoking. Recent studies that have surveyed primary eye care clinicians practicing in various regions of the world, ${ }^{17-23}$ highlight similar deficiencies in care provision in this practice area. Our recent research, which evaluated the self-reported routine practices of Australian optometrists, suggests that less than half of practitioners routinely enquire about their patient's smoking behaviours. ${ }^{21}$ Corroborating this finding are the data in the present survey, in which about only about one-third of patients indicated that their optometrist had asked them about their smoking behaviours. It is therefore interesting then that more than half of respondents were aware of the link between tobacco smoking and blindness. This finding implies the value of advertising campaigns and graphic warnings on eigarette packing in Australia, that have sought to improve publication awareness about the incident risk of blindness with cigarette smoking. ${ }^{31}$ Indeed, Australia is considered a world leader in tobacco control measures, pioneering strategies including the ban of tobacco advertising, and the use of plain packaging on cigarettes, which are now established best practices that have been adopted internationally.

Smoking cessation is a complex issue. Primary eye care clinicians indicate that the care they provide to patients in relation to advice to quit smoking is influenced by multiple factors; it can be limited by consultation time constraints, a perception of sufficient public awareness about the health risks and/or the view that questioning patients about smoking behaviour is relatively awkward and intrusive. ${ }^{21,22}$ Similar perceived barriers were described in a study that surveyed ophthalmologists and optometrists practicing in the United States. ${ }^{32}$ Nevertheless, enhanced recommendations by eye care clinicians to promote smoking cessation, and tobacco cessation more generally, may give rise to immense global health and economic 
benefits. For example, it has been estimated that if cigarette smoking was halved in Australia, cases of AMD would reduce by one-sixth, with savings to the local economy in the order of $\$ 250$ million per year. ${ }^{9}$

Recommendations from health care providers have been shown to be strongly influential for encouraging smoking cessation, with demonstrable positive effects on quit rates. ${ }^{33,34}$ Even rudimentary patient counselling, of less than three minute duration, can increase smoking cessation rates by up to 30 percent. ${ }^{33}$ The American Medical Association recommend for primary health care providers to ask their patients, potentially even those as young as 10 years of age, about their tobacco use, in order to encourage discussions surrounding prevention and cessation. ${ }^{35}$ Although not explicitly investigated in this study, in addition to smoking cessation, related potential topics for patient education could potentially include tobacco prevention (i.e., preventing youth from starting to use tobacco) and/or tobacco protection (e.g., providing advice about the risks of second-hand, also called sidestream, tobacco smoke). Indeed, there is emerging evidence that sidestream smoke has higher concentrations of carcinogens and is more toxic than mainstream (directly inhaled) smoke that can harm the health of non-smokers, and so advice to minimise exposure to this environmental factor is possibly equally as important as tobacco cessation advice. 36

It is becoming globally recognised that eye care professionals have an opportunity to contribute to providing public education about the risks of tobacco use. ${ }^{37}$ There is therefore a need to ensure that eye care professionals are adequately equipped, in terms of training and competence, to discuss smoking behaviours with their patients. A recent review of undergraduate optometry schools in the United Kingdom (UK) concluded that there was a need to enhance practical training to support smoking cessation in the curricula of optometry training, to ensure optometrists are competent in supporting patients to quit smoking. ${ }^{38}$ This finding parallels research that reviewed the coverage of tobacco addiction in UK medical school curricula and confirmed similar deficiencies in physician training in this area. ${ }^{39}$ At present, whether similar scope for improved training in this area exists in the Australian optometric curricula is unclear. However, that our previous research has shown younger Australian optometrists to be significantly less likely to assess patient smoking behaviours than 
more experienced practitioners, implies a potential need for more training in this area. $^{21}$

The present study also shows that half of patients expect their optometrist to ask them about their smoking habits and even more, approximately 70\%, feel comfortable discussing this issue with their optometrist. The potential barrier perceived by optometrists that patients might not be receptive to discussing smoking behaviours is therefore relatively overstated, and implies that the behaviour of the profession is not entirely consistent with patient expectations. A relevant comparison in the medical field relates to patient-doctor discussions surrounding healthcare costs associated with different treatment modalities; although few physicians routinely undertake such discussions, patients' value having these discussions with their doctor. ${ }^{40,} 41$ Interestingly, those respondents who had received optometric care within the past 12 months, were significantly more likely to expect their optometrist to ask about smoking cessation than those whose most recent eye test was more than two years ago. These findings may indicate recent shifts in attitude amongst clinicians in relation to providing care in this area, or poorer recall of this discussion by patients who had their eyes examined a longer time period ago.

Another significant factor affecting patients' expectations regarding eye care was the location of their most recent eye examination. Compared with respondents who selfreported having had this care provided in Australia, those who indicated having their last eye examination in Asia were significantly more likely to expect their optometrist to assess their eye health, ask them about their smoking status and communicate with their general medical practitioner. Unlike in Australia, where routine optometric practice includes ocular health assessment and potentially the prescription of scheduled ocular medicines, in Asia the optometry profession is primarily considered a refraction-based discipline, responsible for determining spectacle and contact lens prescriptions. In this subpopulation of our respondents (7\% of total responses), the survey findings may therefore actually reflect the perceived role of the major eye care providers in these countries, being ophthalmologists.

In general, it was not possible to confirm which clinical provider (i.e., an ophthalmologist or optometrist) provided eye care most recently to respondents. This 
raises the possibility that the reported public perceptions and understanding could be representative of the Australian eye care professions more generally. In the context of respondents who indicated having had their most recent eye examination performed in Australia, we consider this potential confounding factor unlikely, given that the survey population derived from a University clinic population who were attending specifically for optometric care and potential participants were informed that the anonymous survey related to the care provided by their optometrist.

In relation to patient-reported optometric practices in the area of diet and nutritional supplementation, approximately four out of five respondents indicated that their optometrist did not routinely ask them about their diet and nutritional supplement intake. This finding implies a significantly higher level of disengagement from the profession in this domain than was suggested by our 2015 survey of Australian optometrists, in which 60 percent of respondents self-reported routinely counselling patients about diet. ${ }^{21}$ This lack of consistency is not surprising given the known limitations of self-reported behaviours, which rely upon factors such as respondents' introspective abilities, and can have a tendency to err on more favourable reporting. Notably, about 40 percent of respondents in the present study agreed that they expect their optometrist to undertake this line of questioning and the vast majority (about 80 percent) felt comfortable discussing their dietary habits with their optometrist.

It is interesting that younger respondents were significantly more likely to agree that their optometrist had mentioned the influence of diet on their ocular health than older respondents, given that many eye conditions with known dietary influences (e.g., AMD and dry eye disease) are associated with advancing age. This could potentially reflect compromised recall in older participants, although we consider this unlikely given the demographics of the respondents (median age: 31 years, inter-quartile range: 24-47 years). Importantly, clinical advice relating to diet and eye health could involve both a discussion of the merit and/or relative inappropriateness of dietary interventions for specific ocular conditions. For example, in relation to the potential use of nutritional supplements for modulating myopia (as considered by Elliott, 2013), ${ }^{43}$ our findings may reflect optometric advice to younger patients not to consume such supplements with the intent of achieving changes to refractive progression. As it was not the aim of this study to evaluate the rigour of the clinical 
advice provided, we are unable to provide specific comment in relation to whether the recommendations provided by optometrists to patients is consistent with the current, best-available research evidence. A 2013 study of optometric practice behaviours in the UK concluded that there was a need to raise awareness among optometrists of the evidence underpinning the use of nutritional supplements, in order to guide appropriate clinical recommendations in the context of managing AMD. ${ }^{17}$ As discussed in a 2016 editorial in the Journal of the American Medical Association, increasing numbers of clinical trials have, in many cases, demonstrated relatively disappointing results in relation to the potential health benefits of dietary supplementation for treating human disease, with some even showing capacity for harm. ${ }^{42}$ There is therefore a need for health care providers to stay well informed of the literature in this domain, so as to provide relevant, evidence-based advice to their patients. This could be in the form of simple advice, such as that advocated by the Macular Disease Foundation of Australia, which encourages a healthy, balanced diet that includes the intake of coloured vegetables daily and oily fish (e.g., salmon, tuna, sardines) at least twice weekly. More complex, nutrition-focussed healthcare could then be achieved through appropriate co-management with GPs and/or other health professionals, such as dieticians, to achieve desirable lifestyle changes.

Our survey findings indicate that the vast majority of patients (almost 90 percent) expect optometrists to refer them to other allied health professionals, as required. Although we did not include a survey question assessing whether people had previously been offered a referral for inter-professional support by their optometrist, given that only about one-third of respondents responded positively to having been routinely questioned about their smoking status, we would expect even fewer to have been referred for smoking cessation counselling. The same rationale applies to referral to a dietician, with only a minority $(\sim 20 \%)$ of respondents agreeing that they had been routinely questioned about their diet and/or nutritional supplement intake; we would predict very few of these individuals to have received a referral for support to modify this lifestyle behaviour. These findings are important, as in the context of smoking cessation, the offer of advice and support to change behaviour, as distinct from only assessing current behaviour, has been shown to lead to an increase in smoking quit attempts. ${ }^{44}$ Together, these findings imply an opportunity for optometrists to promote inter-disciplinary referral, which patients are receptive to, in order to assist with 
achieving goals relating the modification of lifestyle behaviours with potential effects on eye health.

We acknowledge some limitations to the present study. Survey respondents were a convenience sample of patients attending the University of Melbourne eye care clinic who were required to recall details relating to their prior optometric experiences. Whilst this sample provided a broad cross-sectional representation of patients attending this primary eye care service, there is the potential for self-selection bias and we are unable to assure that the population is fully representative of the Australian public more broadly. For example, the study population included more female $(63 \%)$ than male respondents and most were distributed around a median age of 31 years (inter-quartile range: 24-47 years), which may have implications for the generalisability of the findings. Recall bias, caused by differences in the accuracy or completeness of patients' recollections, may also have affected our findings, however the significance of this effect is minimised by the median time since a patient's last eye examination being relatively short (one year). The number of participants who had undergone their most recent eye test in Asia $(n=15)$ is also relatively low; these data suggest that further study of the apparent effect of the geographic location of a person's last eye examination on their expectations regarding optometric care is warranted. Future research, involving a larger number of sites, including different practice modes and geographic regions, would be beneficial for further investigating these findings.

In conclusion, this study provides the first insight into patients' perceptions and experience with optometric practice in the areas of general health, tobacco smoking and nutrition. Our findings indicate that the majority of patients attending for eye care in an Australian optometry practice recognise the expertise of optometrists in providing care that includes an examination of their ocular health. Furthermore, most patients expect their optometrist to ask them about their smoking and diet habits, and feel comfortable discussing these topics with their optometry care provider. The findings highlight potential scope to improve patient-related guidance in relation to smoking, diet and nutritional supplementation in Australian optometry practice. 


\section{DISCLOSURES}

No authors have any conflicts of interest relating to this research.

\section{ACKNOWLEDGEMENTS}

This work is funded by a 2015 NHMRC Translating Research Into Practice (TRIP) Fellowship to LED (APP1091833).

\section{REFERENCES}

1. Kiely PM (editor). A Global Competency-Based Model of Scope of the Practice of Optometry. 2015, August 2015.

2. Harper R, Creer R, Jackson J, Ehrlich D, Tompkin A, Bowen M, et al. Scope of practice of optometrists working in the UK Hospital Eye Service: a national survey. Ophthal Physiol Opt 2016;36(2):197-206.

3. Willis E. Medical Dominance, the division of labour in Australian Health Care Tasmania, Australia: Allen and Unwin; 1989.

4. Cole BL. A history of Australian optometry. Melbourne, Victoria, Australia: Australian College of Optometry; 2015.

5. Optometry Australia. Practising Optometry in Australia - Scope of Practice. 2016 [cited 1 December 2016]; Available from: http://www.optometry.org.au/aboutus/about-optometry/.

6. Klein R, Klein BE, Linton KL, DeMets DL. The Beaver Dam Eye Study: the relation of age-related maculopathy to smoking. Am J Epidemiol 1993;137(2):190200.

7. Seddon JM, Willett WC, Speizer FE, Hankinson SE. A prospective study of cigarette smoking and age-related macular degeneration in women. JAMA 1996;276(14):1141-6.

8. Downie LE, Keller PR. Nutrition and age-related macular degeneration: research evidence in practice. Optom Vis Sci 2014;91(8):821-31.

9. Deloitte Access Economics - Macular Disease Foundation. 'Eyes on the future - A clear outlook on age-related macular degeneration'. 2011.

10. Thornton J, Edwards R, Mitchell P, Harrison RA, Buchan I, Kelly SP. Smoking and age-related macular degeneration: a review of association. Eye (Lond). 2005;19:935-44. 
11. Smith W, Assink J, Klein R, Mitchell P, Klaver CC, Klein BE, et al. Risk factors for age-related macular degeneration: Pooled findings from three continents. Ophthalmology. 2001;108(4):697-704.

12. Tomany SC, Wang JJ, Van Leeuwen R, Klein R, Mitchell P, Vingerling JR, et al. Risk factors for incident age-related macular degeneration: pooled findings from 3 continents. Ophthalmology. 2004;111(7):1280-7.

13. Khan JC, Thurlby DA, Shahid H, Clayton DG, Yates JR, Bradley M, Moore AT, Bird AC, Genetic Factors in AMD Study Group. Smoking and age related macular degeneration: the number of pack years of cigarette smoking is a major determinant of risk for both geographic atrophy and choroidal neovascularisation. $\mathrm{Br} \mathrm{J}$ Ophthalmol. 2006;90:75-80.

14. Thornton J, Edwards R, Mitchell P, Harrison RA, Buchan I, Kelly SP. Smoking and age-related macular degeneration: a review of association. Eye (Lond). 2005;19(9):935-44.

15. Smith W, Assink J, Klein R, Mitchell P, Klaver CC, Klein BE, et al. Risk factors for age-related macular degeneration: pooled findings from three continents. Ophthalmology. 2001;108:697-704.

16. Vingerling JR, Hofman A, Grobbee DE, de Jong PT. Age-related macular degeneration and smoking. The Rotterdam Study. Arch Ophthalmol. 1996;114(10):1193-6.

17. Lawrenson JG, Evans JR. Advice about diet and smoking for people with or at risk of age-related macular degeneration: a cross-sectional survey of eye care professionals in the UK. BMC Public Health. 2013;13:564.

18. Thompson C, Harrison RA, Wilkinson SC, Scott-Samuel A, Hemmerdinger C, Kelly SP. Attitudes of community optometrists to smoking cessation: an untapped opportunity overlooked? Ophthal Physiol Opt. 2007;27:389-93.

19. Caban-Martinez AJ, Davila EP, Lam BL, Duboy SR, McCollister KE, Fleming LE, et al. Age-Related Macular Degeneration and Smoking Cessation Advice by Eye Care Providers: A Pilot Study. Prev Chron Dis. 2011;8(6):A147.

20. Brûlé J, Abboud C, Deschambault E. Smoking cessation counselling practices among Québec optometrists: evaluating beliefs, practices, barriers and needs. Clin Exp Optom. 2012;95:599-605. 
21. Downie LE, Keller PR. The self-reported clinical practice behaviors of Australian optometrists as related to smoking, diet and nutritional supplementation. PloS One. 2015;10(4):e0124533.

22. Kennedy RD, Spafford MM, Schultz AS, Iley MD, Zawada V. Smoking cessation referrals in optometric practice: a canadian pilot study. Optom Vis Sci 2011;88(6):766-71.

23. Kennedy RD, Spafford MM, Douglas O, Brule J, Hammond D, Fong GT, et al. Patient tobacco use in optometric practice: a Canada-wide study. Optom Vis Sci 2014;91(7):769-77.

24. West R, McNeill A, Raw M. Smoking cessation guidelines for health professionals: an update. Health Education Authority. Thorax. 2000;55(12):987-99. 25. Hom MM, Asbell P, Barry B. Omegas and Dry Eye: More Knowledge, More Questions. Optom Vis Sci 2015;92(9):948-56.

26. Deinema LA, Vingrys AJ, Wong C-Y, Jackson DC, Chinnery HR, Downie LE. A randomized, double-masked, placebo-controlled clinical trial of two forms of omega-3 supplements for treating dry eye disease. Ophthalmology. 2016:S01616420(16)31373-2.

27. Downie LE, Keller PR, Vingrys AJ. An evidence-based analysis of Australian

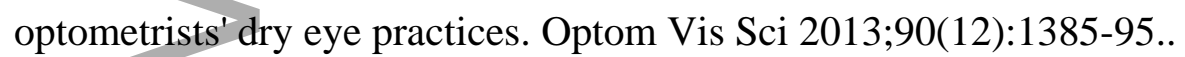

28. Downie LE, Rumney N, Gadd A, Keller PR, Purslow C, Vingrys AJ. Comparing self-reported optometric dry eye clinical practices in Australia and the United Kingdom: is there scope for practice improvement? Ophthalmic Physiol Opt 2016;36(2):140-51.

29. Downie LE, Barrett C, Keller PR. The personal nutrition-related attitudes and behaviors of Australian optometrists: is there evidence for an evidence-based approach? Nutrition 2015;31(5):669-677.

30. Leffondre K, Abrahamowicz M, Siemiatycki J, Rachet B. Modeling smoking history: a comparison of different approaches. Am J Epidemiol 2002;156(9):813-23. 31. Carroll T, Rock B. Generating Quitline calls during Australia's National Tobacco Campaign: effects of television advertisement execution and programme placement. Tob Control 2003;12 Suppl 2:ii40-4.

32. Gordon JS, Andrews JA, Lichtenstein E, Severson HH, Akers L, Williams C. Ophthalmologists' and optometrists' attitudes and behaviours regarding tobacco cessation intervention. Tob Control. 2002;11(1):84-5. 
33. US Department of Health and Human Services. Agency for Healthcare Research and Quality. Clinical Care Guideline. Treating Tobacco Use and Dependence: 2008 Update.

34. Lancaster T, Stead LF. Physician advice for smoking cessation. Cochrane Database Syst Rev. 2004;3:CD000165.

35. American Medical Association. Guidelines for Adolescent Preventive Health Services. Chicago, IL, USA: American Medical Association, 1993.

36. Schick S, Glantz S. Philip Morris toxicological experiments with fresh sidestream smoke: more toxic than mainstream smoke. Tob Control. 2005;14(6):396404..

37. Asfar T, Lam BL, Lee DJ. Smoking causes blindness: time for eye care professionals to join the fight against tobacco. Invest Ophthalmol Vis Sci 2015;56(2):1120-1..

38. Lorencatto F, Harper AM, Francis JJ, Lawrenson JG. A survey of UK optometry trainees' smoking cessation training. Ophthalmic Physiol Opt 2016;36(4):494-502.

39. Raupach T, Al-Harbi G, McNeill A, Bobak A, McEwen A. Smoking cessation education and training in U.K. medical schools: a national survey. Nicotine Tob Res. 2015;17(3):372-5.

40. Alexander GC, Casalino LP, Meltzer DO. Patient-physician communication about out-of-pocket costs. JAMA 2003;290(7):953-8.

41. Irwin B, Kimmick G, Altomare I, Marcom PK, Houck K, Zafar SY, et al. Patient experience and attitudes toward addressing the cost of breast cancer care. The Oncologist. 2014;19(11):1135-40.

42. Cohen PA. The Supplement Paradox: Negligible Benefits, Robust Consumption. JAMA. 2016;316(14):1453-4.

43. Elliott DB. The Bates method, elixirs, potions and other cures for myopia: how do they work? Ophthalmic Physiol Opt 2013;33:75-7.

44. Aveyard P, Begh R, Parsons A, West R. Brief opportunistic smoking cessation interventions: a systematic review and meta-analysis to compare advice to quit and offer of assistance. Addiction 2012;107(6):1066-73. 


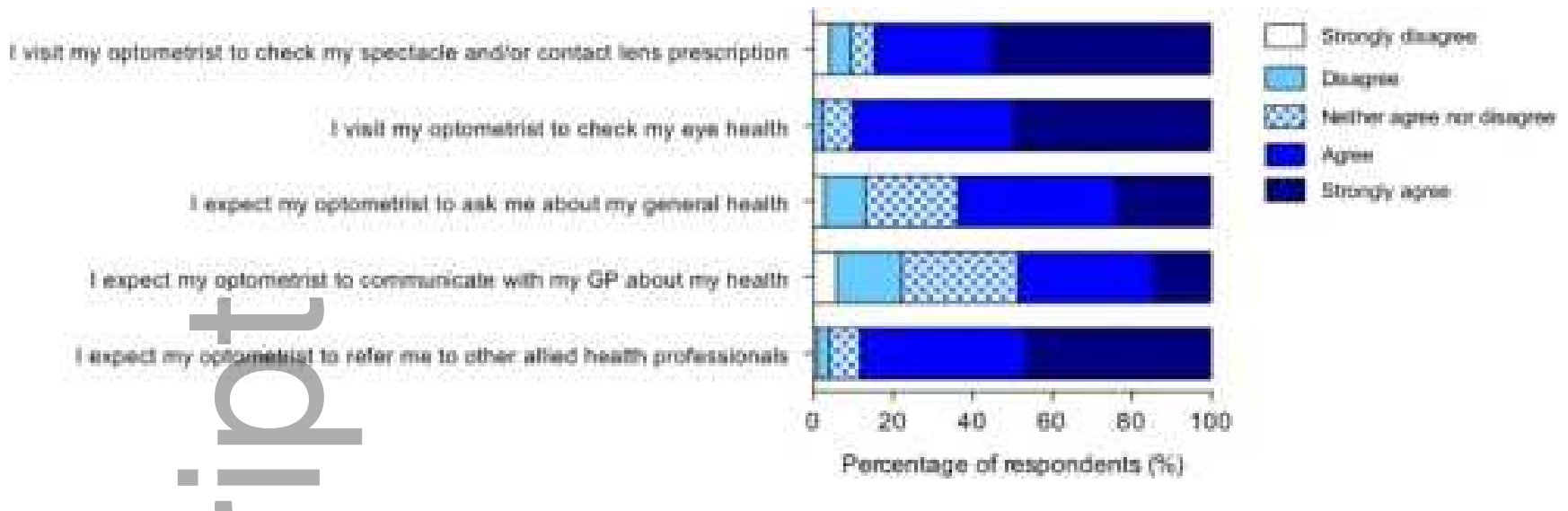

opo_12353_f1.tif 


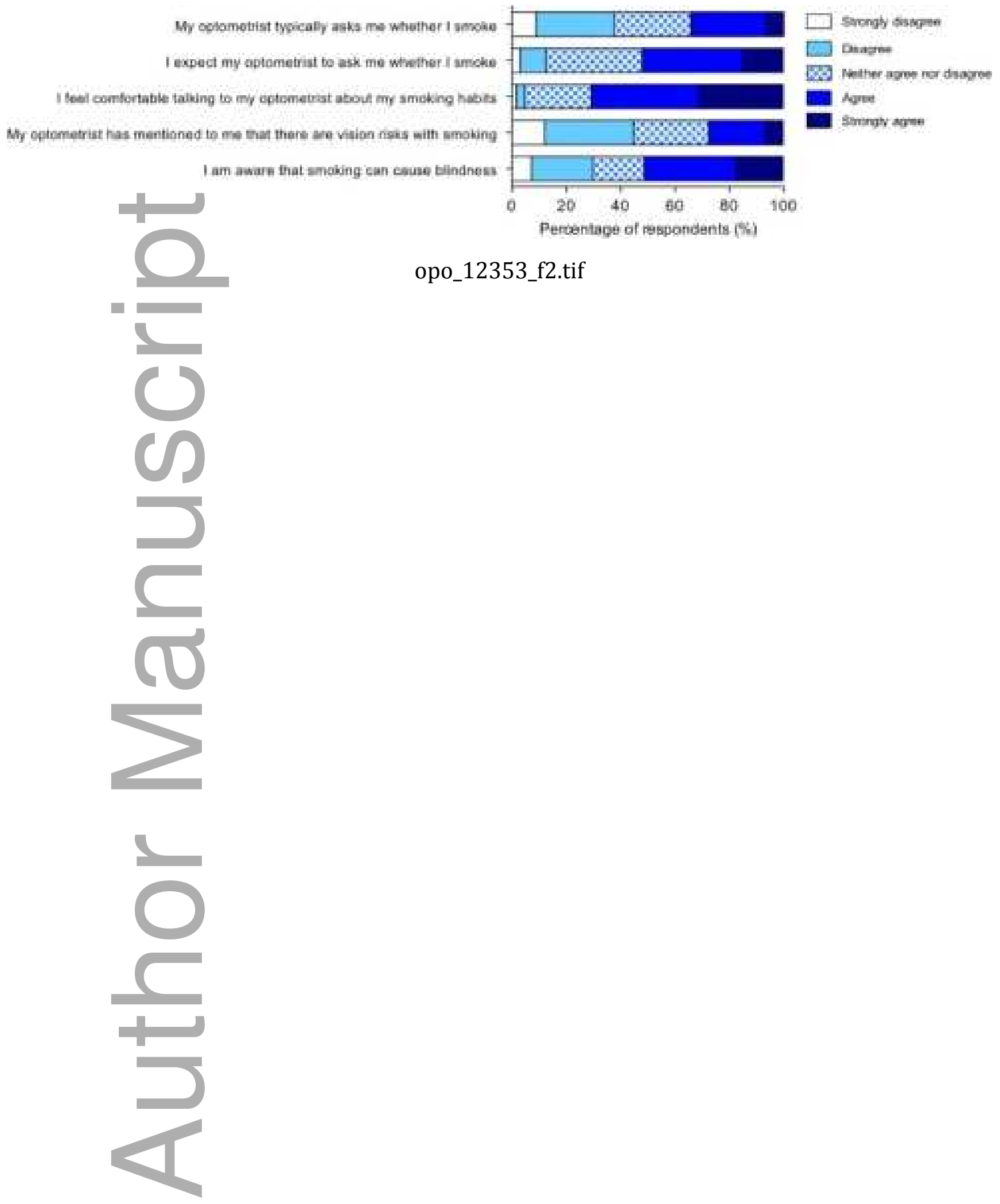

This article is protected by copyright. All rights reserved 


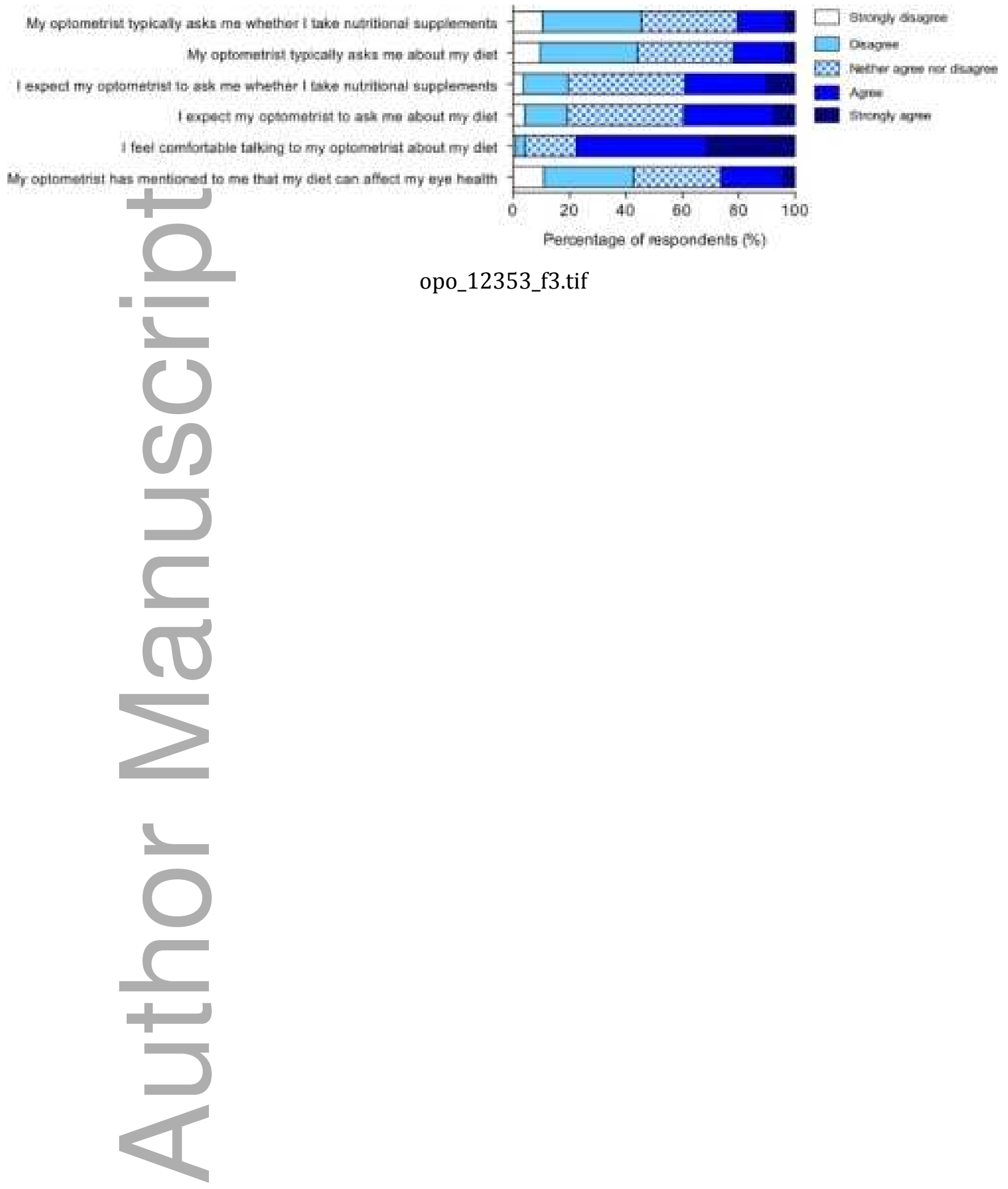




\section{University Library}

\section{- M M N E R VA A gateway to Melbourne's research publications}

Minerva Access is the Institutional Repository of The University of Melbourne

Author/s:

Downie, LE;Douglass, A;Guest, D;Keller, PR

Title:

What do patients think about the role of optometrists in providing advice about smoking and nutrition?

Date:

2017-03-01

Citation:

Downie, L. E., Douglass, A., Guest, D. \& Keller, P. R. (2017). What do patients think about the role of optometrists in providing advice about smoking and nutrition?. OPHTHALMIC AND PHYSIOLOGICAL OPTICS, 37 (2), pp.202-211. https://doi.org/10.1111/opo.12353.

Persistent Link:

http://hdl.handle.net/11343/292452 